\title{
Analisis Komposisi Hasil Tangkapan Bagan Perahu dan Tancap di Perairan Teluk Kupang
}

\author{
Joi A. Surbakti* dan Rikka Welhelmina Sir \\ Program Studi Teknik Budidaya Perikanan, Jurusan Perikanan dan Kelautan, Politeknik Pertanian Negeri Kupang \\ Jl. Prof. Dr. Herman Yohanes Lasiana, Kupang \\ ${ }^{*}$ Corresponding author, e-mail: surbaktijoy@gmail.com
}

\begin{abstract}
ABSTRAK : Salah satu masalah yang dihadapi dalam pemanfaatan sumberdaya ikan adalah kurang selektifnya berbagai jenis alat tangkap yang digunakan oleh para nelayan. Akibatnya adalah tertangkapnya ikan-ikan yang bukan menjadi tujuan penangkapan (bycatch) yang dalam prakteknya sebagian besar ikan-ikan tersebut dibuang ke laut (discarded catch). Penelitian ini bertujuan untuk mengidentifikasi dan menginventarisasi komposisi jenis dan ukuran ikan hasil tangkapandari alat tangkap bagan perahu dan bagan tancap.Lokasi penelitian di Kelurahan Oesapa sebagai sentra pemukiman nelayan bagan perahu danbagan tancap di Kota Kupang dan di Perairan Teluk Kupang.Penelitian ini dilakukan menggunakan metode survei dengan obyek penelitian yaitu: fakta, proses, histori, persepsi tentang perikanan bagan perahu, komposisi jenis dan ukuran ikan tangkapan yang meliputi identifikasi hasil tangkapan, berat (kilogram), jumlah (ekor), panjang cagak (fork length), keliling maksimum (maximum girth), dan lebar badan ikan. Cara mengukur panjang baku pada penelitian ini yaitu jarak garis lurus antara ujung bagian kepala yang paling depan (biasanya ujung salah satu dari rahang yang terdepan) sampai ke pelipatan pangkal sirip ekor.Hasil menunjukkan bahwa jenis ikan yang dominan tertangkap pada bagan perahu adalah ikan teri, peperek dan kembung, sedangkan pada bagan tancap ikan peperek, teri dan tembang.
\end{abstract}

Kata kunci: analisis; bagan perahu; bagan tancap; komposisi; Teluk Kupang

\section{Composition Analysis of Boat Lift Net and Fix Lift Net Operating in Kupang Bay}

ABSTRACT: One of the problems faced in using fish resources is the lack of selectivity of various types of fishing gear used by fishermen. The result is the catch of fish which is not the purpose of arrest(bycatch) which in practice most of the fish are discarded catch. This study aims to identify and inventory the type and size offish catches (boat lift net and fix lift net). Research location in Oesapa village in Kupang City in Kupang Bay. This research was conducted by survey method with research object that is: fact, process, history, perception of fishery boat lift net, species composition and size of fish catch including identification of catch, weight (kilogram), number (tail), length of fork length, maximum girth, and fish body width, mesh size. The method of measuring the standard length in this study is the distance of a straight line between the tip of the front of the head (usually the tip of one of the leading jaws) to the tail fin's base. The results show that the dominant fish species in boat lift net are anchovies, pony fishes, and long-jawed mackereland, from fix lift net, are pony fishes, anchovy and sardine.

Keywords: analysis; boat lift net; composition; fix lift net; Kupang Bay

\section{PENDAHULUAN}

Bagan adalah salah satu jenis alat tangkap yang memiliki target tangkapan ikan-ikan dengan nilai ekonomis tinggi (Borges et al., 2005; Broadhurst et al., 2006). Dari segi pembuatan dan operasi bagan baik perahu maupun tancap relatif ekonomi dan dapat dioperasikan dalam beberapa tahun. Jumlah bagan yang ada di sekitar Teluk Kupang ada berjumlah 8 buah yang terdiri dari 4 bagan perahu dan 4 bagan tancap. Potensi jumlah ikan yang ditangkap tidak mampu memenuhi kebutuhan pasar ikan pelagis di Kota Kupang. Keberadaan bagan ini dari ekonomi 
cukup membantu kehidupan para nelayan.Salah satu masalah yang dihadapi dalam pemanfaatan sumberdaya ikan adalah kurang selektifnya berbagai jenis alat tangkap yang digunakan oleh para nelayan.Akibatnya adalah tertangkapnya ikan-ikan yang bukan menjadi tujuan utamapenangkapan (bycatch) yang dalam prakteknya sebagian besar ikan-ikan tersebut dibuang ke laut (discarded catch) (Salim, 2017; Muhajirah, 2018; Yuda, 2012; Jukri, 2013 )

Bagan merupakan salah satu jaring angkat yang dioperasikan di perairan pantai pada malam hari dengan menggunakan cahaya lampu sebagai faktor penarik ikan Menurut Wiyono (2006) di Indonesia bagan diperkenalkan pada awal tahun 1950 dan sekarang telah banyak mengalami perubahan. Bagan pertama sekali digunakan oleh nelayan Makassar dan Bugis di Sulawesi Selatan, kemudian nelayan daerah tersebut membawanya kemana-mana dan akhirnya hampir dikenal di seluruh Indonesia, termasuk di Perairan Teluk Kupang, Nusa Tenggara Timur.

Salah satu masalah yang dihadapi dalam pemanfaatan sumberdaya ikan adalah kurang selektifnya berbagai jenis alat tangkap yang digunakan oleh para nelayan Karena kebutuhan ikan yang cukup banyak dan tanpa melihat ukuran ikan yang ditangkap maka terkadang ikan yang ditangkap tidak layak (Mahendra et al., 2015). Penelitian ini bertujuan untuk mengidentifikasi dan menginventarisasi komposisi jenis dan ukuran ikan hasil tangkapanutama dan sampingan (bycatch) dari alat tangkap bagan perahu dan bagan tancap. Lokasi penelitian di Kelurahan Oesapa sebagai sentra pemukiman nelayan Bagan Perahu di Kota. Penelitian ini dilakukan menggunakan metode survei dengan obyek penelitian yaitu bagan perahu dan bangan tancap.Melalui penelitian ini diharapkan dapat memberikan informasi analisis komposisi jenis dan ukuran ikan hasil tangkapan bagan perahu dan bagan tancap

\section{MATERI DAN METODE}

Lokasi penelitian ditentukan secara purposive di Kelurahan Oesapa dan Kelapa lima sebagai sentra pemukiman nelayan Bagan Perahu dan Tancap di Kota Kupang dan di Perairan Teluk Kupang sebagai lokasi penangkapan ikan (fishing ground) alat tangkap bagan perahu. Penelitian ini secara keseluruhan dilakukan dari Agustus sampai November 2017. Pengumpulan data dilakukan dengan menggunakan deskriptif survei dan wawancara serta data sekunder dari instansi terkait. Data sekunder berupa data yang didapat dari hasil wawancara yang dilakukan dengan nelayan. Penelitian dalam pengidentifikasian ikan terhadap hasil tangkapan nelayan berdasarkan buku pedoman dari FAO (Food Agriculture Organization) dan buku pedoman Saanin (1984); Lubis et al., (2016) dan website Fishbase.com.

\section{HASIL DAN PEMBAHASAN}

Kegiatan penelitian telah dilaksanakan di delapan bagan milik nelayan setempat yang bermukim di sepanjang pesisir pantai Oesapa dan Kelapa Lima yang berada di perairan Teluk Kupang.Delapan bagan ini terdiri dari empat bagan perahu dan empat bagan tancap. Responden yang berjumlah delapan ini diambil sebagai sampel dikarenakan jumlah bagan tancap maupun bagan perahu yang ada di perairan teluk kupang berdasarkan jumlah bagan tancap dan bagan perahu yang masing-masing berjumlah delapan.

Berdasarkan hasil wawancara dengan pemilik bagan perahu, usaha bagan perahu ini telah ditekuni kurang lebih 20 tahun yang lalu. Dari keempat pemilik bagan ini, semuanya adalah penduduk pendatang yang berasal dari Sulawesi, dengan tingkat pendidikan minimal SD dan Maksimal SMP sesuai dengan (Mulyadi, 2007). Umur responden (pemilik) juga bervariasi yaitu berkisar dari 39-72 tahun. Kepemilikan bagan tancap semuanya oleh penduduk lokal yang memang telah mewarisi bagan tersebut dari orang tua/turun temurun sebagai usaha keluarga.Tingkat Pendidikan pemilik bagan tancap semuanya SMA dan umurnya bervariasi dari 28-52 tahun. Menurut Kusnadi (2007) yang menjadi persoalan sosial di kalangan masyarakat nelayan diantaranya yaitu, semakin meningkatnya kelangkaan sumber daya perikanan, kerusakan ekosistem pesisir dan laut, serta keterbatasan kualitas dan kapasitas teknologi penangkapan, rendahnya kualitas sumber daya manusia, ketimpangan akses terhadap sumber daya perikanan, serta lemahnya proteksi kebijakan dan dukungan fasilitas pembangunan untuk masyarakat nelayan.Berdasarkan hasil wawancara dengan responden, hampir responden secara otodidak 
mendapatkan ilmu dan keahlian dalam bidang perikanan tanpa melalui pendidikan formal hanya satu orang responden sebagai pemilik bagan tancap yang berpendidikan SMK Perikanan jurusan penangkapan.

Dari keempat bagan perahu dan keempat bagan tancap yang telah diteliti di sepanjang perairan di Kelurahan Oesapa dan Kelapa Lima didapatkan jenis ikan yang mendominasi adalah ikan teri (Engraulis encrasicolus), denganj umlah yang cukup melimpah diikuti oleh ikan peperek (Leiognathusequulus), dan ikan kembung (Rastrelligerkanagurta) dibandingkan dengan jenis ikan yang lain (Tabel 1). Jenis ikan yang lain adalah kelompok ikan pelagis kecil yaitu ikan tembang (Sardinnella lemuru), ikan belo-belo (Sardinella sirin). Selain itu juga didapatkan kelompok ikan demersal berupa kakap merah (Lutjanuscampechanus) hanya sebanyak 3 ekor. Pada salah satu bagan ini didapatkan bycatch berupa ikan pari merah (Himanturavarnak) dengan ukuran lebar 33 $\mathrm{cm}$, panjang badan $29 \mathrm{~cm}$, panjang ekor $29 \mathrm{~cm}$ dan berat ikan sebesar $1,1 \mathrm{~kg}$. Jumlah populasi terbanyak yang didapat nelayan pada bangan tancap adalah ikan (Nuchequula equulus) diurutan kedua adalah ikan teri (Engraulidae) serta ikan tembang (Sardinnella).

Nelayan Teluk Kupang menggunakan bagan perahu sebagai alat tangkap untuk menangkap ikan. Dalam proses penangkapan ikan dengan bagan,atraktor cahaya yang digunakan bertujuan untuk mengumpulkan ikan yang mempunyai sifat fototaksis positif. Ikan yang bersifat fototaksis positif akan berkumpul didaerah cahaya lampu sehingga memudahkan nelayan dalam melakukan upaya penangkapan (Hasan, 2008). Berbeda dengan budidaya perikanan yang dapatmenggambungkan beberapa spesies hasil laut menjadi satukegiatan produksi secara bersamaan (Surbakti et al., 2019) perikanan tangkap adalah proses penangkapan hasil laut yangdiambil secara langsung dari perairan. Hasil tangkapan bagan apung selama penelitian berjumlah 12 jenis. Penelitian yang menghasilkan tangkapan sebanyak 12 jenis ikan. Persentase lkan yang ditangkap pada bagan apung sebesar 49,8 \% dari jumlah keseluruhan ikan yang ditangkap. Sementara persentase jumlah ikan teri yang ditangkap pada bagan tancap adalah $42,08 \%$ dari hasil tangkapan.

Tabel 1. Hasil tangkapan bagan perahu

\begin{tabular}{lcccccc}
\hline $\begin{array}{c}\text { Jenis } \\
\text { Ikan }\end{array}$ & Jumlah populasi & $\begin{array}{c}\text { Panjang } \\
(\mathrm{cm})\end{array}$ & $\begin{array}{c}\text { Berat/ } \\
\text { Ekor }(\mathrm{g})\end{array}$ & $\begin{array}{c}\text { Panjang total } \\
(\mathrm{cm})\end{array}$ & $\begin{array}{c}\text { Lebar ikan } \\
(\mathrm{cm})\end{array}$ & $\begin{array}{c}\text { Keliling maksimum } \\
(\mathrm{cm})\end{array}$ \\
\hline Kembung & 150 & 21,30 & 133,30 & 19,30 & 4,20 & 10,70 \\
Kembung padi & 20 & 10,77 & 7,83 & 7,60 & 1,50 & 4,20 \\
Parang-parang & 2 & 18,55 & 103,35 & 14,00 & 5,25 & 11,20 \\
Alu-alu & 63 & 15,39 & 48,35 & 13,32 & 2,66 & 7,16 \\
Peperek & 402 & 16,24 & 28,98 & 13,49 & 5,87 & 13,85 \\
Teri & 914 & 7,76 & 4,80 & 6,63 & 1,19 & 4,76 \\
Cumi-cumi & 3 & 11,02 & 26,40 & 0,00 & 2,39 & 5,40 \\
Biji nangka & 50 & 11,13 & 25,70 & 9,43 & 3,17 & 7,63 \\
Tembang & 103 & 5,52 & 2,80 & 4,55 & 0,93 & 3,00 \\
Terbang & 4 & 7,30 & 3,70 & 6,20 & 1,40 & 4,50 \\
Tulang-tulang & 118 & 14,65 & 28,00 & 11,85 & 3,60 & 10,25 \\
Kakap merah & 3 & 41,50 & 4335,30 & 33,73 & 14,84 & 35,97 \\
Pari & 1 & 33,50 & 1111,00 & 0,00 & 32,60 & 65,20 \\
\hline
\end{tabular}

Tabel 2. Ikan hasil tangkapan bagan tancap

\begin{tabular}{lcccccc}
\hline $\begin{array}{l}\text { Jenis } \\
\text { Ikan }\end{array}$ & Jumlah populasi & $\begin{array}{c}\text { Panjang } \\
(\mathrm{cm})\end{array}$ & $\begin{array}{c}\text { Berat/ } \\
\text { Ekor }(\mathrm{g})\end{array}$ & $\begin{array}{c}\text { Panjang total } \\
(\mathrm{cm})\end{array}$ & $\begin{array}{c}\text { Lebar ikan } \\
(\mathrm{cm})\end{array}$ & $\begin{array}{c}\text { Keliling maksimum } \\
(\mathrm{cm})\end{array}$ \\
\hline Tembang & 102 & 5,515 & 2,8 & 4,55 & 0,93 & 3 \\
Teri & 526 & 7,9 & 3,75 & 6,6325 & 1,05 & 3,4 \\
Terbang & 4 & 7,3 & 3,7 & 6,2 & 1,4 & 4,5 \\
Alu-alu & 50 & 9,7 & 7,5 & 8,015 & 1,865 & 4,7 \\
Peperek & 565 & 9,95 & 17,15 & 8,2 & 3,8 & 8,2 \\
Parang-parang & 3 & 6,1 & 181,7 & 0 & 4,7 & 10,8 \\
\hline
\end{tabular}


Hasil analisis data ukuran panjang hasil tangkapan utama menunjukkan bahwa ikan tembang (Sardinella), ikan kembung (Rastrelliger spp.) dan Peperek (Leiognathus equulus),yang tertangkap sebagian besar dinyatakan belum layak tangkap karena ukurannya rata-rata belum melebihi ukuran ikan pertama kali matang gonad.Jumlah ikan tembang dan ikan kembung yang tertangkap, termasuk kategori belum layak tangkap sesuai dengan pernyataan Syamsuddin (2008).

Ikan layak tangkap dalam kegiatan penangkapan adalah ikan yang telah memasuki fase reproduksi. Fekunditas yang terjadi pada spesies ikan lebih sering dihubungkan dengan panjang tubuh ikan dari pada berat ikan, sebab ukuran panjang ikan penyusutannya relatif kecil dibandingkan penyusutan berat Kondisi ini terlihat bahwa ukuran panjang ikan pada saat diukur di atas bagan perahu sesuai dengan Rudha Alamsyah (2014), tidak mengalami penyusutan panjang pada saat dilakukan pengukuran kembali di darat. Namun ukuran berat ikan saat diukur di atas perahu, mengalami penyusutan setelah dilakukan pengukuran berat ikan pada saat di darat.Hal ini berhubungan dengan kandungan air yang masih terdapat di dalam tubuh ikan pada saat baru diangkut dari dalam air. Saat ikan tiba di darat, kadar air di dalam tubuh ikan menjadi berkurang. Hubungan ukuran panjang ikan terhadap volume hasil tangkapan menunjukkan tingkat eksploitasi pemanfaatan sumberdaya perikanan pada ukuran tertentu.

Hasil tangkapan ikan yang diperoleh memiliki ukuran panjang yang berbeda-beda pada masing-masing spesies . sesuai Sudirman et al. (2011). Kondisi ini dapat menyebabkan ikan-ikan tidak dapat menjadi dewasa dan ekosistem perairan akan terganggu sesuai dengan pernyataan (Surbakti, et al., 2019). Ikan Kakap Merah memiliki ukuran berkisar $41 \mathrm{~cm}$ sesuai dengan Mallawa (2012), dengan ini menunjukkan bahwa belum dapat dikategorikan layak tangkap pada alat tangkap bagan perahu belum mencapai panjang maksimum ikan untuk memijah (lenght at first maturity). Tertangkapnya spesies ikan tersebut pada alat tangkap disebabkan oleh tersedianya makanan yang dibutuhkan oleh spesies-spesies tersebut, dan juga dipengaruhi adanya pasang surut. Hasil tangkapan utama dari jenis ikan lain tetap diambil oleh nelayan untuk dijual walaupun dari segi ukuran masih belum layak untuk ditangkap

Tabel 3. Persentase layak tangkap berdasarkan ukuran panjang ikan tembang,kembung dan peperek pada bagan perahu

\begin{tabular}{|c|c|c|c|c|c|c|c|c|}
\hline \multirow{3}{*}{ Kriteria } & \multirow{2}{*}{\multicolumn{2}{|c|}{$\begin{array}{c}\begin{array}{c}\text { Tembang } \\
\text { (Sardinnela) }\end{array} \\
\text { Jumlah }\end{array}$}} & \multirow{2}{*}{\multicolumn{2}{|c|}{$\begin{array}{c}\text { Kembung } \\
\text { (Rastrelliger sp.) } \\
\text { Jumlah } \\
\end{array}$}} & \multirow{2}{*}{\multicolumn{2}{|c|}{$\begin{array}{c}\text { Peperek } \\
\text { (Leiognathus equulus) } \\
\text { Jumlah } \\
\end{array}$}} & \multicolumn{2}{|c|}{ Total } \\
\hline & & & & & & & \multirow{2}{*}{ Ikan } & \multirow{2}{*}{$\%$} \\
\hline & Ikan & $\%$ & Ikan & $\%$ & Ikan & $\%$ & & \\
\hline Layak tangkap & 46 & 44,66 & 54 & 36 & 25 & 6,22 & 125 & 19,08 \\
\hline $\begin{array}{l}\text { Tidak layak } \\
\text { tangkap }\end{array}$ & 57 & 55,33 & 96 & 64 & 377 & 93,78 & 530 & 80,92 \\
\hline Total & 50 & 100 & 150 & 100 & 100 & 100 & 200 & 100 \\
\hline
\end{tabular}

Tabel 4. Persentase layak tangkap berdasarkan ukuran Panjang ikan tembang, kembung dan peperek pada bagan tancap

\begin{tabular}{|c|c|c|c|c|c|c|c|c|}
\hline \multirow{3}{*}{ Kriteria } & \multirow{2}{*}{\multicolumn{2}{|c|}{$\begin{array}{c}\begin{array}{c}\text { Tembang } \\
\text { (Sardinnela) }\end{array} \\
\text { Jumlah }\end{array}$}} & \multirow{2}{*}{\multicolumn{2}{|c|}{$\begin{array}{c}\begin{array}{c}\text { Alu-alu } \\
\text { (Sphyraena) }\end{array} \\
\text { Jumlah }\end{array}$}} & \multirow{2}{*}{\multicolumn{2}{|c|}{$\begin{array}{c}\text { Peperek } \\
\text { (Leiognathus } \\
\text { equulus) }\end{array}$}} & \multicolumn{2}{|c|}{ Jumlah } \\
\hline & & & & & & & \multirow{2}{*}{ Ikan } & \multirow{2}{*}{$\%$} \\
\hline & Ikan & $\%$ & Ikan & $\%$ & Ikan & $\%$ & & \\
\hline \multirow{2}{*}{$\begin{array}{l}\text { Layak tangkap } \\
\text { Tidak layak } \\
\text { tangkap }\end{array}$} & 40 & 39,22 & 25 & 50 & 100 & 17,99 & 165 & 23,31 \\
\hline & 62 & 60,78 & 25 & 50 & 456 & 82,01 & 543 & 76,69 \\
\hline Total & 102 & 100 & 50 & 100 & 556 & 100 & 708 & 100 \\
\hline
\end{tabular}




\section{KESIMPULAN}

Engraulis encrasicolus dan Leiognathus equulus mendominasi hasil tangkapan bagan perahu dan bagan tancap. Engraulis encrasicolus, Leiognathus equulus, Sphyraena, Sardinella sirin memiliki kelimpahan yang tinggi, baik hasil tangkap dengan bagan tancap maupun bagan perahu. Lutjanus campechanus memiliki ukuran panjang total yang tertinggi. Ikan peperek, kembung dan tembang yang tertangkap memiliki ukuran yang tidak layak tangkap. Dari hasil yang ditemukan pada penelitian ini dapat disimpulkan keanekaragaman ikan total hasil tangkapan tergolong tinggi dan banyak.

\section{DAFTAR PUSTAKA}

Alamsyah, R. \& Musbir, F.A. 2014. Struktur Ukuran Dan Ukuran Layak Tangkap Ikan Cakalang (Katsuwonus pelamis) Di Perairan Teluk Bone. Jurnal Sains \& Teknologi, 14(1):95-100.

Badan Pusat Statistik Kota Kupang. 2012. Kota Kupang dalam Angka 2011. Kota Kupang: Badan Pusat Statistik.

Borges, L., Rogan, E. \& Officer, R. 2005. Discarding by The Demarsal Fishery in The Waters Around Ireland. Fisheries Research, 76:1-13.

Broadhurst, M.K., Millar, R.B., Wooden, M.E.L. \& Macbeth, W.G. 2006. Optimising Codend Configuration in a Multispecies Demarsal Trawl Fishery. Fisheries Management and Ecology, 13:81-92.

Muhajirah, E., \& Sara, L. 2018. Keanekaragaman dan hasil tangkapan sampingan Jaring Insang di perairan Lalowaru Kabupaten Konawe Selatan. Jurnal Manajemen Sumber Daya Perairan, $3(1): 43-54$

Salim, G. \& Kelen, P.G., 2017. Analisis Identifikasi Komposisi Hasil Tangkapan Menggunakan Alat Tangkap Jaring Insang Hanyut (Drift Gill Net) di Sekitar Pulau Bunyu, Kalimantan Utara. Jurnal Harpodon Borneo, 10(1):13-22

Hanura. 2010. Distribusi Cahaya Lampu dan Tingkah Laku Ikan Pada Proses Penangkapan Bagan Perahu di Perairan Maluku Tengah. Jurnal Amanisal, 1(1):22-29.

Jukri, M., Emiyarti \& Kamri, S. 2013. Keanekaragaman Jenis Ikan di Sungai Lamunde Kecamatan Watubangga Kabupaten Kolaka Provinsi Sulawesi Tenggara. Jurnal Mina Laut Indonesia, $1(1): 23-37$

Kusnadi. 2008. Akar Kemiskinan Nelayan. Yogyakarta: Lkis Yogyakarta.

Lubis, A.Y., Efawani, \& Windarti. 2016. Re-Inventarisasi Jenis Ikan Di Sungai Sail Anak Sungai Siak Kota Pekanbaru Riau. Jurnal Onlime Mahasiswa Faperi, 3(2):36-45

Mahendra, F., Fitri, A.D.P. \& Arsiyanto, 2015. Analisis Tangkapan Alat Modifikasi Di Perairan Tawang Kendal Jawa Tengah. Journal of Fisheries Resources Utilization Management and Technology 4(1):60-69.

Mulyadi. 2007. Ekonomi Kelautan. Jakarta: PT Raja Grafindo Persada

Mulyana, D. 2002. Metodologi Penelitian Kualitatif. Bandung : PT Remaja Rosdakarya

Mallawa, A. 2012. Aspek perikanan dan Prediksi Tangkapan Per Unit Upaya ikan cakalang (Katsuwonus pelamis) di perairan Luwu Teluk Bone, Sulwesi Selatan. Fakultas Ilmu Kelautan dan Perikanan. Universitas Hasanuddin.

Syamsuddin. 2008. Analisis Pengembangan Sumberdaya Ikan Cakalang (Katsuwonus pelamis linneus) Ramah Lingkungan dan Berkelanjutan. Jurnal Sains dan Teknologi. 8(1):38-49.

Sudirman, Hade, A.R. \& Sapruddin. 2011. Perbaikan Tingkat Keramahan Lingkungan Alat Tangkap Bagan Tancap Melalui Perbaikan Selektivitas Mata Jaring. Bulletin Penelitian LP2M Universitas Hasanuddin. 
Surbakti, J.A. \& Sir, R. 2019. Tingkat Keramahan Lingkungan Alat Tangkap Bagan Di Perairan Oesapa Teluk Kupang, Nusa Tenggara Timur. Saintek Perikanan: Indonesian Journal of Fisheries Science and Technology, 15(1):41-45. Doi: 10.14710/ijfst.15.1.41-45

Surbakti, J.A., Dewi, I.A.L., Alamsjah, M., \& Lamid, M. 2019. Development of water and nutrient management modelsto improve multitrophic seafarming productivity. IOP Conf. Series: Earth and Environmental Science, 236(2019):012020 Doi:10.1088/1755-1315/236/1/012020

Wiyono, E.S., Yamada, S., Tanaka, E., Arimoto, T. \& Kitakado, T. 2006. Dynamic of Fishing Gear Allocation by Fisheris in Small-Scale Coastal Fisheries of Palabuhan ratu Bay, Indonesia. Fisheries Management and Ecology. 13(3):185-195

Yuda, L.K. \& Khan, A.M., 2012. Tingkat Keramahan Lingkungan Alat Tangkap Di Perairan Pelabuhan Ratu. Jurnal perikanan dan Kelautan, 3(3):7-13 